\title{
Thermal, chemical and chemothermal denaturation of yeast enolase
}

\author{
Ping Huang ${ }^{1}$ and Aichun Dong* \\ Department of Chemistry and Biochemistry, University of Northern Colorado, Greeley, CO 80639, USA
}

\begin{abstract}
We studied the temperature- and denaturant-induced denaturation of yeast enolase by means of Fourier transform infrared spectroscopy. The temperature-induced denaturation/aggregation of the enzyme in the absence of denaturant was highly cooperative and occurred between 55 and $65^{\circ} \mathrm{C}$ with a midpoint of $\sim 58^{\circ} \mathrm{C}$. Above $55^{\circ} \mathrm{C}$, the intensity at $1656 \mathrm{~cm}^{-1}$ (predominantly $\alpha$-helix) decreases as a function of temperature, accompanied by the appearance of two new bands at 1622 and $1696 \mathrm{~cm}^{-1}$, indicating the formation of intermolecular $\beta$-sheet aggregates. Five clearly defined isosbestic points were observed, indicating a two-state conformational transition. Addition of a non-denaturing concentration of gdn $\mathrm{HCl}(0.4 \mathrm{M})$ caused the thermal denaturation/aggregation of the enzyme to proceed faster, but this revealed no unfolding intermediate. The gdnHClinduced unfolding was first detected at a gdnHCl concentration of above $0.4 \mathrm{M}$, evidenced by loss of $\alpha$-helix and $\beta$-sheet structures as functions of denaturant concentration. The fully unfolded state was reached at a gdnHCl concentration of $1.6 \mathrm{M}$. A significant amount of intermolecular $\beta$-sheet aggregate was detected at gdnHCl concentrations between 0.6 and $1.0 \mathrm{M}$, which disappeared as the denaturant concentration increased further. The gdnHCl-unfolded state is a heterogeneous ensemble of turns, helix/loops, and random structures, which continues to change at higher concentrations of denaturant.
\end{abstract}

\section{Abbreviations:}

FT-IR, Fourier transform infrared spectroscopy; gdnHCl, guanidine hydrochloride.

\section{Introduction}

Enolase (2-phospho-D-glycerate hydrolyase, EC 4.2.1.11) is a glycolic protein that catalyzes the dehydration of 2-phospho-D-glycerate to form phosphoenolpyruvate. Yeast enolase exists as a dimeric protein composed of two chemically identical subunits [1,2] with 436 residues each [3-6]. Each monomer contains two metal binding sites, the "conformational" (site I) and the "catalytic" (site II), and has an absolute requirement for a certain divalent cation $\left(\mathrm{Mg}^{2+}\right.$ or $\left.\mathrm{Mn}^{2+}\right)$ for enzymatic activity [4,7]. Binding of metal ions at site I induces conformational changes at the enzyme active site, which enables the binding of substrate or substrate analogue [8]. Following the binding of the first metal ion and substrate, binding of metal ions at site II initiates the catalytic reaction [9].

$\mathrm{X}$-ray crystal structures of yeast enolase in both the apo and holo forms are currently available [10,11]. High-resolution crystal structure revealed that yeast enolase is a modified $(\beta \alpha)_{8}$ barrel protein with a core structure arrangement of $\beta \beta \alpha \alpha(\beta \alpha)_{6}$ topology [10,11]. Each monomer of the dimeric enzyme consists of two domains: a smaller $\mathrm{N}$-terminal domain with a three-stranded antiparallel $\beta$-meander, followed by a long $\alpha$-helix and three shorter helices, and a larger C-terminal domain with an 8 -fold $\beta \alpha$-barrel

\footnotetext{
${ }^{1}$ Present address: Atrix Laboratories, Inc., 2579 Midpoint Drive, Fort Collins, CO 80522, USA.

*Corresponding author: Department of Chemistry and Biochemistry, University of Northern Colorado, Greeley, CO 80639, USA. Tel.: +1 970351 1284; Fax: +1 970351 1269; E-mail: adong@ unco.edu.
} 
motif. Unlike the classical $(\beta \alpha)_{8}$ barrel of triose-phosphate isomerase (TIM), the inner $\beta_{8}$-barrel of yeast enolase is not an uninterrupted parallel $\beta$-sheet, but with the $\beta_{2}$-strand runs antiparallel to the $\beta_{1}$ and $\beta_{3}$ strands $[10,11]$. Although the evolutional link between members of the enolase superfamily and the wider superfamily of phosphate-binding TIM barrels could be established via a sequence family of unknown structure and function, the UPF0034 proteins, and a circular permutation theory, the unique arrangement of $\beta \beta \alpha \alpha(\beta \alpha)_{6}$ of enolase has not been illustrated [12].

Despite its unique $\beta \alpha$-barrel arrangement, the thermal stability and chemical unfolding of yeast enolase have not been carefully studied. It is unclear whether the $\beta \beta \alpha \alpha(\beta \alpha)_{6}$ barrel topology and the antiparallel interruption affect the thermal stability and chemical denaturant-induced unfolding of the protein in relation to the archetypal $(\beta \alpha)_{8}$ barrel protein with an uninterrupted parallel $\beta$-sheet. In the present work, we carried out studies on heat-induced denaturation/aggregation and chemical denaturant guanidine hydrochloride $(\mathrm{gdnHCl})$ induced unfolding of yeast enolase using Fourier transform infrared spectroscopy (FT-IR). The results of this study were compared with the reported experimental data on the heat- and gdnHCl-induced denaturation for TIM obtained with various techniques. FT-IR spectroscopy has proven to be a valuable tool for studying protein denaturation/aggregation due to its insensitivity to the interference by light scattering. It has been used to monitor the denaturation processes of proteins induced by various denaturation factors including thermal, chemical or a combination of chemical and thermal factors [13-15].

The thermal aggregation profiles of yeast enolase in the absence or presence of non-denaturing concentration of gdn $\mathrm{HCl}(0.4 \mathrm{M})$ revealed that the thermal denaturation of the enzyme is highly cooperative and describable with a two-state model. The midpoint temperature $\left(\sim 58^{\circ} \mathrm{C}\right)$ of thermal denaturation of yeast enolase is comparable to the values reported for the archetypal $(\beta \alpha)_{8}$-barrel protein TIM of various species $\left(54-60^{\circ} \mathrm{C}\right)$ [16-18]. The denaturant-induced unfolding occurred at gdnHCl concentrations between 0.4 and $1.6 \mathrm{M}$ with a midpoint around $0.8 \mathrm{M}$, which is comparable to the values $(0.5-1.1 \mathrm{M})$ reported for TIM of various species [19,20].

\section{Materials and methods}

\subsection{Materials}

Enolase (Baker's yeast, E6126) was purchased from Sigma and used without further purification. Guanidine hydrochloride $(\mathrm{gdnHCl})$ was SigmaUltra grade. The stock solutions of proteins were prepared by dissolving lyophilized proteins in $50 \mathrm{mM}$ potassium phosphate buffer, $\mathrm{pH} 7.2$, and dialyzed overnight against the same buffer. The protein concentration was determined spectrophotometrically $\left(\varepsilon_{280}=0.89 \mathrm{ml} \mathrm{mg}^{-1} \mathrm{~cm}^{-1}\right)$ using a molecular weight of $46,500 \mathrm{Da}$ for the monomer [5,21]. The stock solution of gdn $\mathrm{HCl}$ was prepared in $50 \mathrm{mM}$ potassium phosphate buffer at a concentration of $6 \mathrm{M}$ and $\mathrm{pH}$ adjusted with $\mathrm{KOH}$ solution. $\mathrm{GdnHCl}$ concentration was determined using a refractometer and following equation [22]:

$$
[\operatorname{gdnHCl}]=57.147(\Delta N)+38.68(\Delta N)^{2}-9.160(\Delta N)^{3},
$$

where $\Delta N$ is the difference between the refractive index of a gdnHCl solution and that of a buffer. Samples for chemical denaturation analysis were prepared by mixing together aliquots of stock solutions of protein, gdnHCl and buffer. Resultants were equilibrated for 30 minutes at room temperature. Final concentrations of the protein samples were $20 \mathrm{mg} / \mathrm{ml}$. 


\subsection{FT-IR spectroscopy}

Protein samples were placed in a heatable liquid IR cell (Graseby Specac) with $\mathrm{CaF}_{2}$ windows and a 6- $\mu \mathrm{m}$ spacer. Infrared spectra were measured with a Nicolet 730 FT-IR Spectrometer equipped with a dTGS detector and processed with Omnic software (Nicolet). For each spectrum, a 128-scan interferogram was collected in single beam mode with a $4 \mathrm{~cm}^{-1}$ resolution. Reference spectra were recorded under identical scan conditions with only the corresponding buffer or buffer/gdnHCl in the cell. The temperature at which a spectrum was acquired was controlled within $0.5^{\circ} \mathrm{C}$ using a custom-built Peltier cell temperature controller. Spectral acquisition at a given temperature required approximately 6 minutes (i.e., dwell time at the given temperature). The average heating rate between spectral acquisition temperatures was $1.5^{\circ} \mathrm{C} / \mathrm{min}$. Protein spectra were obtained according to previously established criteria and double-subtraction procedure $[23,24]$. Second-derivative spectra were obtained with a 7-point SavitskyGolay derivative function. All second-derivative spectra were baseline corrected and area normalized as previously described [14] after being imported into BGRAMS/386 software (Galactic Industries). Final spectra were treated with a $2 \times$ interpolate function and plotted with a SigmaPlot 5 software (Jandel Scientific). Secondary structure content of yeast enolase in the native state was determined by curve-fitting analysis of the inverted second-derivative spectrum as described previously [25].

To compare the overall structural similarity between the native and denatured states as a function of temperature, the fractions of area overlap were calculated using normalized second-derivative spectra as described previously [26]. The correlation coefficient ( $r$ value) was calculated by the following formula [27,28]:

$$
r=\frac{\sum\left(x_{i} y_{i}\right)}{\sqrt{\sum x_{i}^{2} y_{i}^{2}}}
$$

where $x_{i}, y_{i}=$ intensity of (reference spectrum, comparison spectrum) at wavenumber $(i)$. The value of $r$ equals 1 when there is no conformational change in the protein. The larger the changes in conformation, the greater the differences between the spectra and the smaller the value of $r$.

\section{Results}

\subsection{Thermally induced structural transition}

Figure 1 shows the primary infrared spectra of yeast enolase as a function of temperature. The most intense band between 1700 and $1600 \mathrm{~cm}^{-1}$ is the amide I band, which arises primarily from the $\mathrm{C}=\mathrm{O}$ stretching vibration of the peptide linkages that constitute the backbone structure of the protein $[29$, 30]. At lower temperatures $\left(25-55^{\circ} \mathrm{C}\right)$, yeast enolase exhibits its amide I band maximum at $1655 \mathrm{~cm}^{-1}$, indicating the presence of predominant $\alpha$-helix structure $[23,30]$. As temperature increases to above $55^{\circ} \mathrm{C}$, the intensity at $1655 \mathrm{~cm}^{-1}$ decreases dramatically, which is accompanied by increases of intensity at 1696 and $1622 \mathrm{~cm}^{-1}$. The latter are indicative of formation of intermolecular $\beta$-sheet aggregates [14]. The band between 1600 and $1500 \mathrm{~cm}^{-1}$ is the amide II band, which arises mainly from an out-ofphase combination of $\mathrm{N}-\mathrm{H}$ in-plane bending and $\mathrm{C}-\mathrm{N}$ stretching vibrations of peptide linkages [29]. The amide II band maximum of yeast enolase was observed at $1549 \mathrm{~cm}^{-1}$ at lower temperatures and shifted gradually to $1538 \mathrm{~cm}^{-1}$ during the course of thermal denaturation. It is generally believed that the amide 


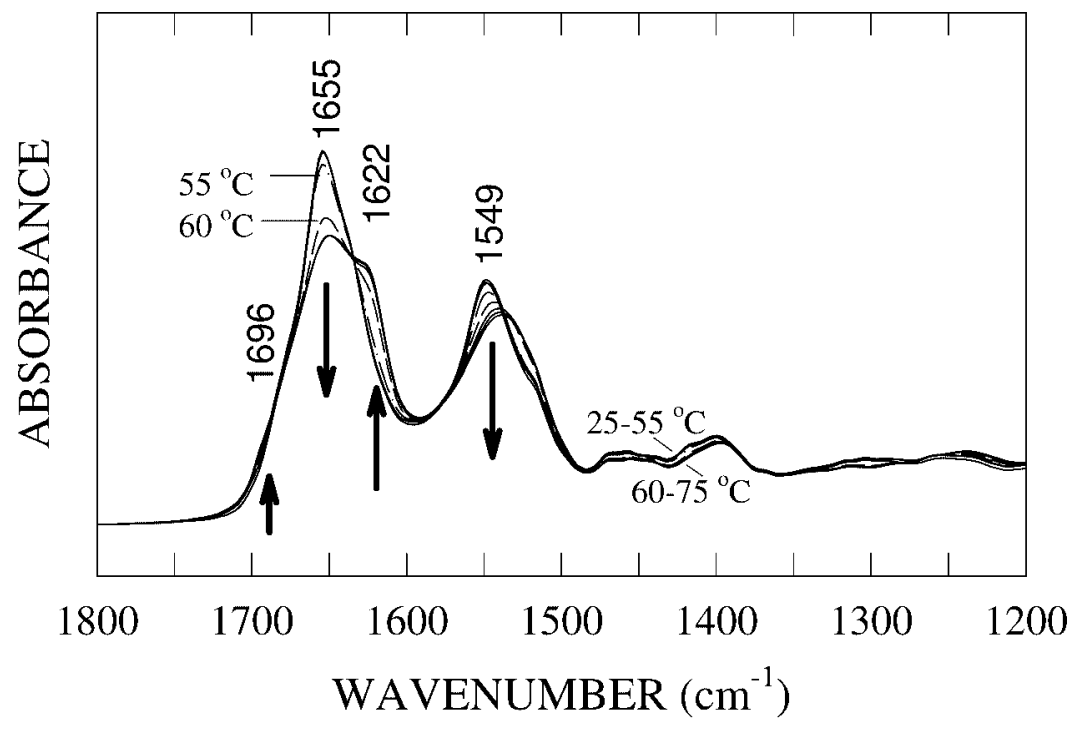

Fig. 1. The primary spectra of yeast enolase in $50 \mathrm{mM}$ potassium phosphate buffer (pH 7.2) as a function of temperature. The spectra were recorded at $25,35,45,55,60,65,70$ and $75^{\circ} \mathrm{C}$. The spectral contributions from liquid and gaseous water have been removed as described under Methods and materials.

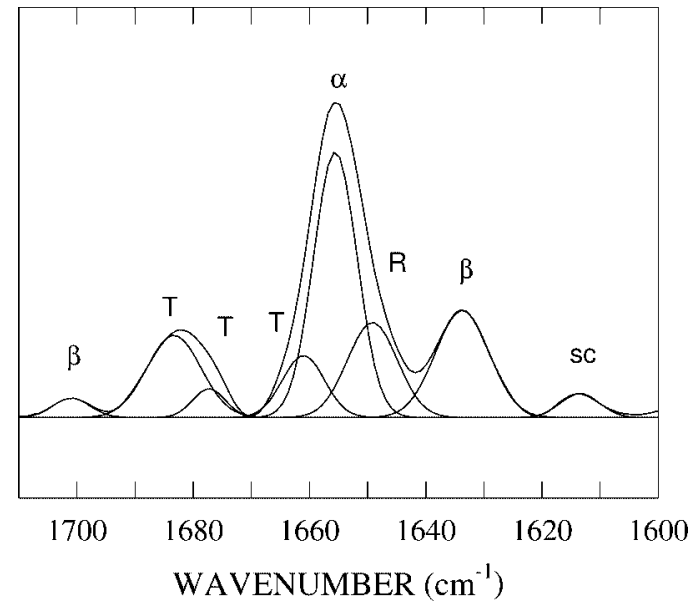

Fig. 2. The curve-fitted inverted second-derivative amide I spectrum of yeast enolase at $25^{\circ} \mathrm{C}$. The inversion of second-derivative spectrum was done by factoring by -1 . The curve-fitting was carried out as described under Materials and methods.

II band is less useful in protein secondary structure determination. A red-shift in frequency was also observed in the amide III region $\left(1350-1220 \mathrm{~cm}^{-1}\right)$ as a function of temperature. This is consistent with the assignments for $\alpha$-helix $\left(1330-1300 \mathrm{~cm}^{-1}\right)$ and $\beta$-sheet $\left(1255-1220 \mathrm{~cm}^{-1}\right)$ in this region [31] and reflects the conformational transition from an $\alpha$-helix predominant to a $\beta$-sheet predominant structure. Furthermore, It is noteworthy that the bands at 1458 and $1381 \mathrm{~cm}^{-1}$, assignable to the asymmetric and symmetric angle bending modes of side-chain $\mathrm{CH}_{3}$ groups [29], respectively, were found in two distinct groups, the native $\left(25-55^{\circ} \mathrm{C}\right)$ and the aggregated $\left(60-75^{\circ} \mathrm{C}\right)$. The intensities of $\mathrm{CH}_{3}$ vibrations of the aggregated state were significantly weaker than that of the native state.

To obtain more detailed information about the secondary structures of the enzyme, we carried out the 
Table 1

Frequencies, relative areas and assignments of second-derivative infrared amide I components of yeast enolase in $\mathrm{H}_{2} \mathrm{O}$ solution ${ }^{\mathrm{a}}$

\begin{tabular}{ccl}
\hline Frequency $\left(\mathrm{cm}^{-1}\right)$ & Band area $(\%)$ & Assignment \\
\hline 1701 & 2.3 & $\beta$-sheet \\
1683 & 14.4 & turns \\
1677 & 3.1 & turns \\
1661 & 8.5 & 3 10-helix \& type III turn \\
1656 & 37.6 & $\alpha$-helix \\
1649 & 15.4 & random \\
1634 & 18.7 & $\beta$-sheet \\
\hline
\end{tabular}

${ }^{\mathrm{a}}$ The amide I band assignments were made on the basis of previous FT-IR spectroscopic studies of other globular proteins in $\mathrm{H}_{2} \mathrm{O}$ solutions $[23,24]$.

Table 2

Comparison of the secondary structure of yeast enolase determined by X-ray crystallography and FT-IR spectroscopy ${ }^{\mathrm{a}}$

\begin{tabular}{|c|c|c|c|c|c|c|}
\hline \multirow[t]{2}{*}{ Method } & \multicolumn{5}{|c|}{ Secondary structure $(\%)$} & \multirow[t]{2}{*}{ Ref. } \\
\hline & $\alpha$-helix & $\begin{array}{l}310 \text {-helix \& } \\
\text { type III turn }\end{array}$ & $\beta$-sheet & $\begin{array}{c}\text { Turns } \\
\text { (-type III) }\end{array}$ & Random & \\
\hline \multicolumn{7}{|c|}{ Apoenzyme } \\
\hline X-ray & 37.3 & $3.4+6.4$ & 17.2 & 22.0 & $(17.1)^{\mathrm{d}}$ & $3 \mathrm{ENL}^{\mathrm{b}}$ \\
\hline FT-IR & 37.6 & 8.5 & 21.0 & 17.5 & 15.4 & This work \\
\hline \multicolumn{7}{|c|}{ Holoenzyme } \\
\hline X-ray & 37.3 & $3.4+6.4$ & 17.2 & 22.0 & $(17.1)^{\mathrm{d}}$ & $4 \mathrm{ENL}^{\mathrm{c}}$ \\
\hline $\begin{array}{l}\text { a The bands } \\
\text { spectroscop } \\
\text { be PDB entry } \\
{ }^{\mathrm{c}} \text { PDB entry } \\
\text { PDB }\end{array}$ & $\begin{array}{l}\text { 10-helix } \\
\text { discussi } \\
{[11] .} \\
{[57] .}\end{array}$ & d type III tu & annot & parated & n each otl & by infrare \\
\hline
\end{tabular}

second-derivative analysis to reveal underlying amide I components. Quantitative analysis by the curvefitting was performed on the spectrum of the native state obtained at $25^{\circ} \mathrm{C}$ (Fig. 2). A total of eight band components were revealed under the amide I contour. Among them, seven are known to associate with various secondary structural elements and one $\left(1613 \mathrm{~cm}^{-1}\right)$ has been generally assigned to the side-chain vibrations of amino acid residues [32]. According to the previous studies of other globular proteins in $\mathrm{H}_{2} \mathrm{O}$ solutions [23,24], the following amide I band assignments can be made: $\alpha$-helices $\left(1656 \mathrm{~cm}^{-1}\right)$, $\beta$-sheets $\left(1634\right.$ and $\left.1701 \mathrm{~cm}^{-1}\right)$, turns $\left(1683,1677\right.$, and $\left.1661 \mathrm{~cm}^{-1}\right)$ and random structure $\left(1649 \mathrm{~cm}^{-1}\right)$. It shows that yeast enolase contains a $37.6 \% \alpha$-helix, $21 \% \beta$-sheet, $8.5 \% 3_{10}$-helix and type III turn, $17.5 \%$ other turns, and $15.4 \%$ random structures (Table 1 ). The result agrees well with the values of $37.3 \% \alpha$-helix and $17.2 \% \beta$-sheet structures reported by X-ray crystallographic analysis (PDB-3 ENL and 4ENL) (Table 2).

Figure 3 shows the second-derivative spectra of enolase in the amide I region as a function of temperature. At temperatures below $55^{\circ} \mathrm{C}$, the spectra of enolase retained all its native-like features. As temperature increased further, however, the intensities at $1656\left(\alpha\right.$-helix) and $1634 \mathrm{~cm}^{-1}$ (native $\beta$-sheet) decreased dramatically, accompanied by the appearance of two new bands at 1622 and $1696 \mathrm{~cm}^{-1}$, indicative of intermolecular $\beta$-sheet aggregates [14]. Five isosbestic points were observed at 1690, 1664, 


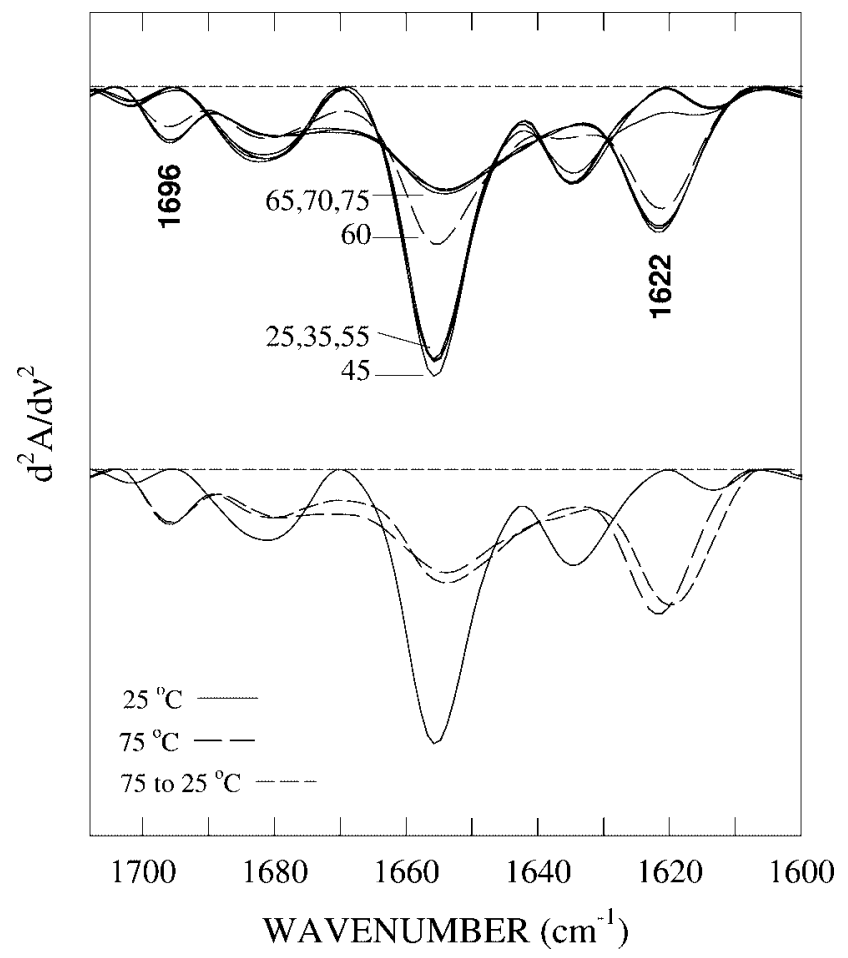

Fig. 3. Second-derivative spectra of yeast enolase in the amide I region as a function of temperature. (Top) The spectra recorded at $25,35,45,55,60,65,70$ and $75^{\circ} \mathrm{C}$. (Bottom) The spectra recorded at 25 and $75^{\circ} \mathrm{C}$ and the spectrum recorded at $25^{\circ} \mathrm{C}$ after being cooled down from $75^{\circ} \mathrm{C}$.

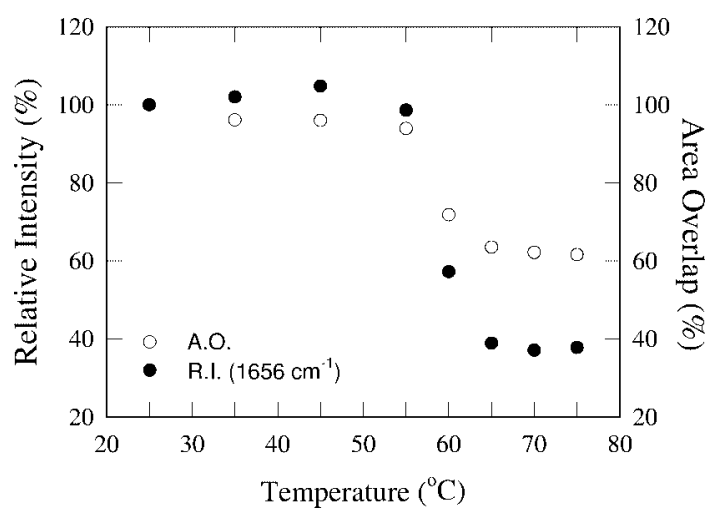

Fig. 4. The plots of relative intensities at $1656 \mathrm{~cm}^{-1}$ and area overlap as functions of temperature. The intensity was calculated as the difference between the peak maximum and baseline. The intensity value measured at $25^{\circ} \mathrm{C}$ was used as the value of $100 \%$.

1646,1640 and $1629 \mathrm{~cm}^{-1}$. This result suggests that yeast enolase underwent a two-state thermal transition from the native state (dimer) to the aggregated state (assumable monomers). After being cooled from 75 to $25^{\circ} \mathrm{C}$, the second-derivative spectrum of enolase exhibited all spectral features of that obtained at $75^{\circ} \mathrm{C}$, except a ca $2 \mathrm{~cm}^{-1}$ red-shift (from 1622 to $1620 \mathrm{~cm}^{-1}$ ) at the band assigned to the intermolecular $\beta$-sheet aggregates, indicating an irreversible thermal denaturation process. 
To quantitatively describe the thermally induced conformational transition of the enzyme, we employed two independent methods: area overlap and relative intensities. Figure 4 shows the plot of the area overlap in the amide I region between the spectra of the native and aggregated states, as well as the plot of changes in relative intensities at $1656 \mathrm{~cm}^{-1}$ (predominantly $\alpha$-helix, Fig. 2), as functions of temperature. For a selected variable, the changes in the amide I area overlap between the spectra of reference (native state) and samples reflect the changes in global structure [26]. On the other hand, the changes in the relative intensity of a selected amide I component reveal the changes in specific secondary structure [14]. Both plots show that the thermally induced conformational transition occurs between temperatures 55 and $65^{\circ} \mathrm{C}$ with midpoint of $\sim 58^{\circ} \mathrm{C}$.

\subsection{Chemically induced structural transition}

Figure 5 shows the second-derivative spectra of yeast enolase in the amide I region as a function of gdnHCl concentration. In the presence of low concentrations $(0.2-0.4 \mathrm{M})$ of gdnHCl, a small intensity increase at $1656 \mathrm{~cm}^{-1}(\alpha$-helix) was observed, indicating a slight increase in the content of $\alpha$-helix

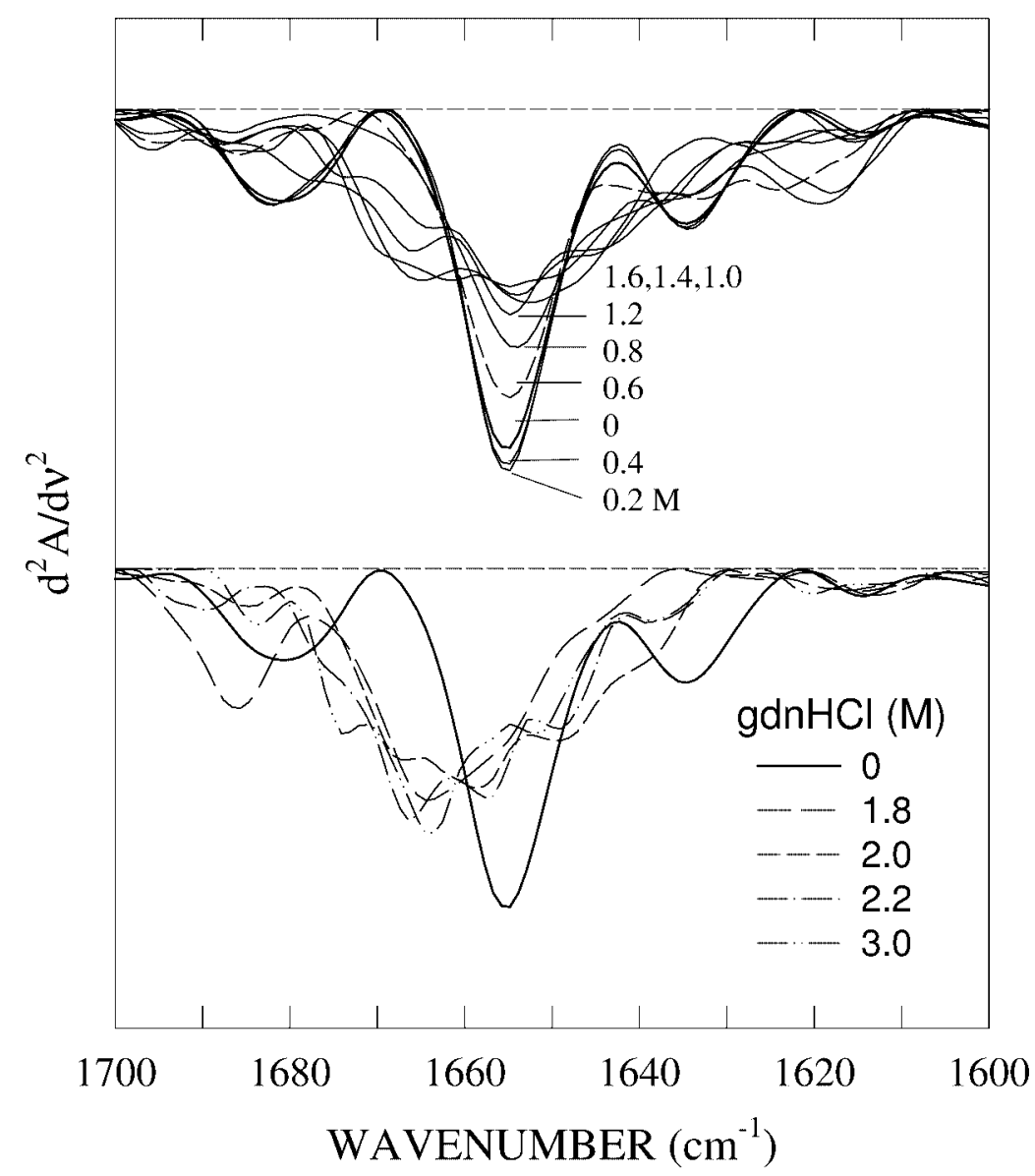

Fig. 5. Second-derivative spectra of yeast enolase in the amide I region as a function of gdnHCl concentration. (Top) The spectra recorded at gdnHCl concentrations of $0,0.2,0.4,0.6,0.8,1.0,1.2,1.4$ and $1.6 \mathrm{M}$. (Bottom) The spectra recorded at gdnHCl concentrations of 1.8, 2.0, 2.5 and 3.0 M. The spectrum recorded in the absence of gdnHCl was included in the lower panel for comparison. 
structure. However, as gdnHCl concentration increased, the intensity of the $1656 \mathrm{~cm}^{-1}$ band gradually decreased, accompanied by the appearance of new bands between 1670 and $1660 \mathrm{~cm}^{-1}$, a region generally associated with $\beta$-turn $\left(1672 \pm 3 \mathrm{~cm}^{-1}\right)$ and $3_{10}$-helix/type III turn $\left(1663 \pm 3 \mathrm{~cm}^{-1}\right)$ structures [23,29]. In the presence of $1.6 \mathrm{M} \mathrm{gdnHCl}$, the $1656 \mathrm{~cm}^{-1}$ band was no longer clearly identifiable, indicating a full disruption of the native $\alpha$-helix structure. However, the residual structures continued to change at higher gdnHCl concentrations (1.8-3.0 M). Multiple band components were observed between 1690-1665 ( $\beta$-turns) and near 1658 ( $\alpha$-helix/loop), 1648 (random), and 1638 ( $\beta$-sheet) $\mathrm{cm}^{-1}$ [23,33,34]. This result suggests that gdnHCl-induced unfolding of yeast enolase proceeds in two distinctly different stages: disruption of the native secondary structures and various unfolded states. The latter indicates that the gdnHCl-unfolded state is a dynamic, heterogeneous ensemble of unfolded conformations containing $\beta$-turn, helix/loop, and random structures. A transient appearance of two bands at 1696 and $1621 \mathrm{~cm}^{-1}$, indicative of the intermolecular $\beta$-sheet aggregate, was observed, in various degree, in the presence of $0.6,0.8$, and $1.0 \mathrm{M} \mathrm{gdnHCl}$. The two bands disappeared as the concentration of gdnHCl increased above 1.2 M. No clear defined isosbestic point was observed, which suggests multiple states conformational transitions. Figure 6 shows the plots of amide I area overlap and relative intensities at $\sim 1656 \mathrm{~cm}^{-1}$ as functions of gdnHCl concentration. Both plots show that yeast enolase unfolded between 0.4 and $1.6 \mathrm{M}$ gdnHCl with midpoint of $\sim 0.8 \mathrm{M}$.

\subsection{Chemothermally induced structural transition}

In an effort to trap any possible intermediate state during thermal denaturation, we performed the thermal experiments in the presence of two different concentrations $(0.4$ and $0.6 \mathrm{M})$ of gdnHCl. From gdnHCl-induced unfolding profile (Fig. 6), we learned that yeast enolase retained its native or native-like conformation in the presence of $0.4 \mathrm{M} \mathrm{gdnHCl}$ at $25^{\circ} \mathrm{C}$. It became partially unfolded and even aggregated (small fraction) in the presence of 0.6-1.0 M gdnHCl (Fig. 5). Recently, Dong and colleagues [15] reported that in the presence of a non-denaturing concentration of gdnHCl, it was possible to populate and thus trap the intermediate state during thermal denaturation of three $\alpha$-helix predominant proteins. Here, we are interested in how a non-denaturing $(0.4 \mathrm{M})$ and a partial-denaturing $(0.6 \mathrm{M})$ concentration of gdnHCl might affect differently the thermal aggregation process of the enzyme.

Figures 7 and 8 show the second-derivative spectra of yeast enolase recorded in the presence of 0.4 and $0.6 \mathrm{M} \mathrm{gdnHCl}$, respectively, as functions of temperature. The thermal aggregation process of the enzyme in the presence of gdnHCl started at a much lower temperature than that of the absence of gdnHCl. Figure 9 shows the plots of relative intensity changes at $\sim 1656 \mathrm{~cm}^{-1}$ (predominantly $\alpha$-helix) with or without $\mathrm{gdnHCl}$ as functions of temperature. In the absence of gdnHCl, the thermal aggregation of enolase was observed between 55 and $65^{\circ} \mathrm{C}$ with a midpoint of $\sim 58^{\circ} \mathrm{C}$, whereas in the presence of $0.4 \mathrm{M}$ gdnHCl, the aggregation process occurred at a much lower temperature range $\left(25-45^{\circ} \mathrm{C}\right)$ with a midpoint of $\sim 38^{\circ} \mathrm{C}$. The midpoint shifted even lower $\left(\sim 27^{\circ} \mathrm{C}\right)$ in the presence of $0.6 \mathrm{M}$ gdnHCl. However, no intermediate state was detectable in both cases. The results indicate that the thermal aggregation of yeast enolase, with or without low concentration of gdnHCl, is a two-state process involving only the native and aggregated states.

\section{Discussion}

Protein folding/unfolding and aggregation are arguably among the most important processes studied in molecular biophysics and structural biology [35-37]. In efforts to elucidate the mechanism by which 


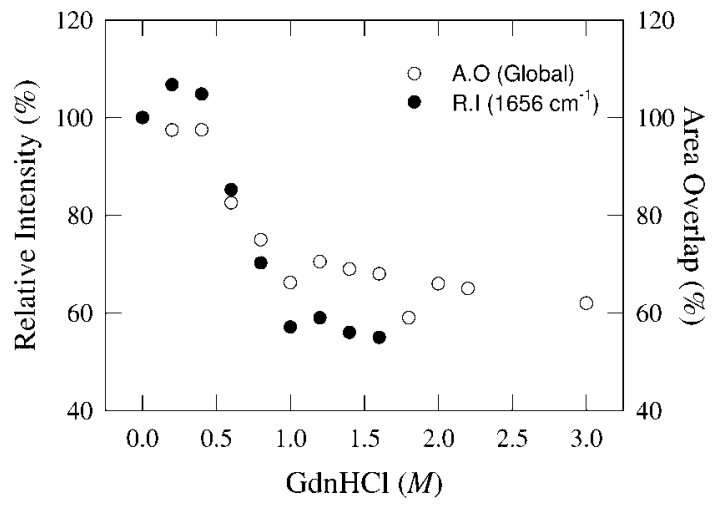

Fig. 6. The plots of relative intensities at $1656 \mathrm{~cm}^{-1}$ and area overlap as functions of gdnHCl concentration. The intensity at $1656 \mathrm{~cm}^{-1}$ (predominantly $\alpha$-helix) was calculated as the difference between the peak maximum and baseline. The intensity value measured at $25^{\circ} \mathrm{C}$ without gdnHCl was used as the value of $100 \%$.

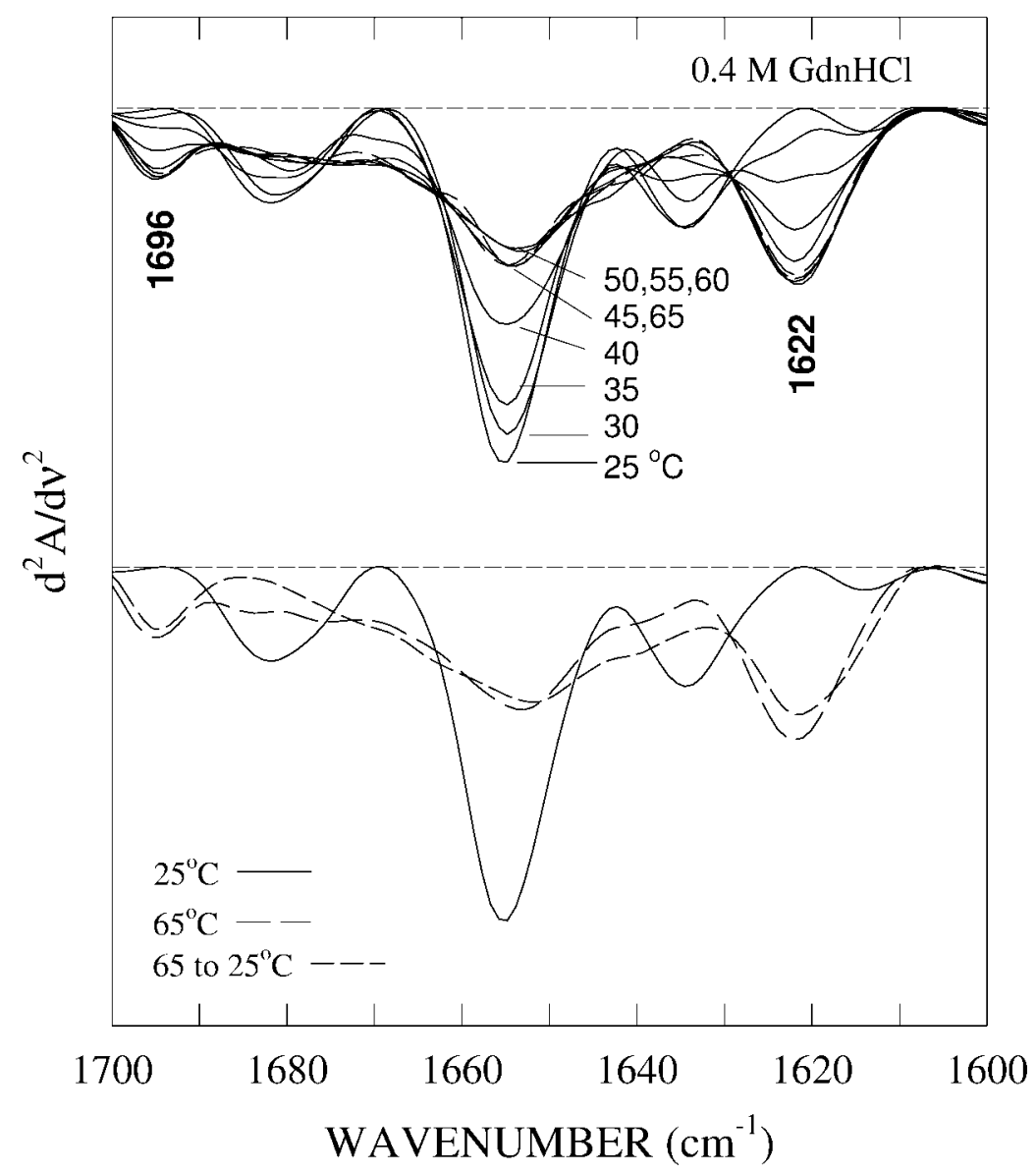

Fig. 7. The second-derivative spectra of yeast enolase in the presence of $0.4 \mathrm{MgdnHCl}$ as a function of temperature. (Top) The spectra were recorded at 25, 35, 40, 45, 50, 55, 60 and $65^{\circ} \mathrm{C}$. (Bottom) Spectra selected for comparison. 


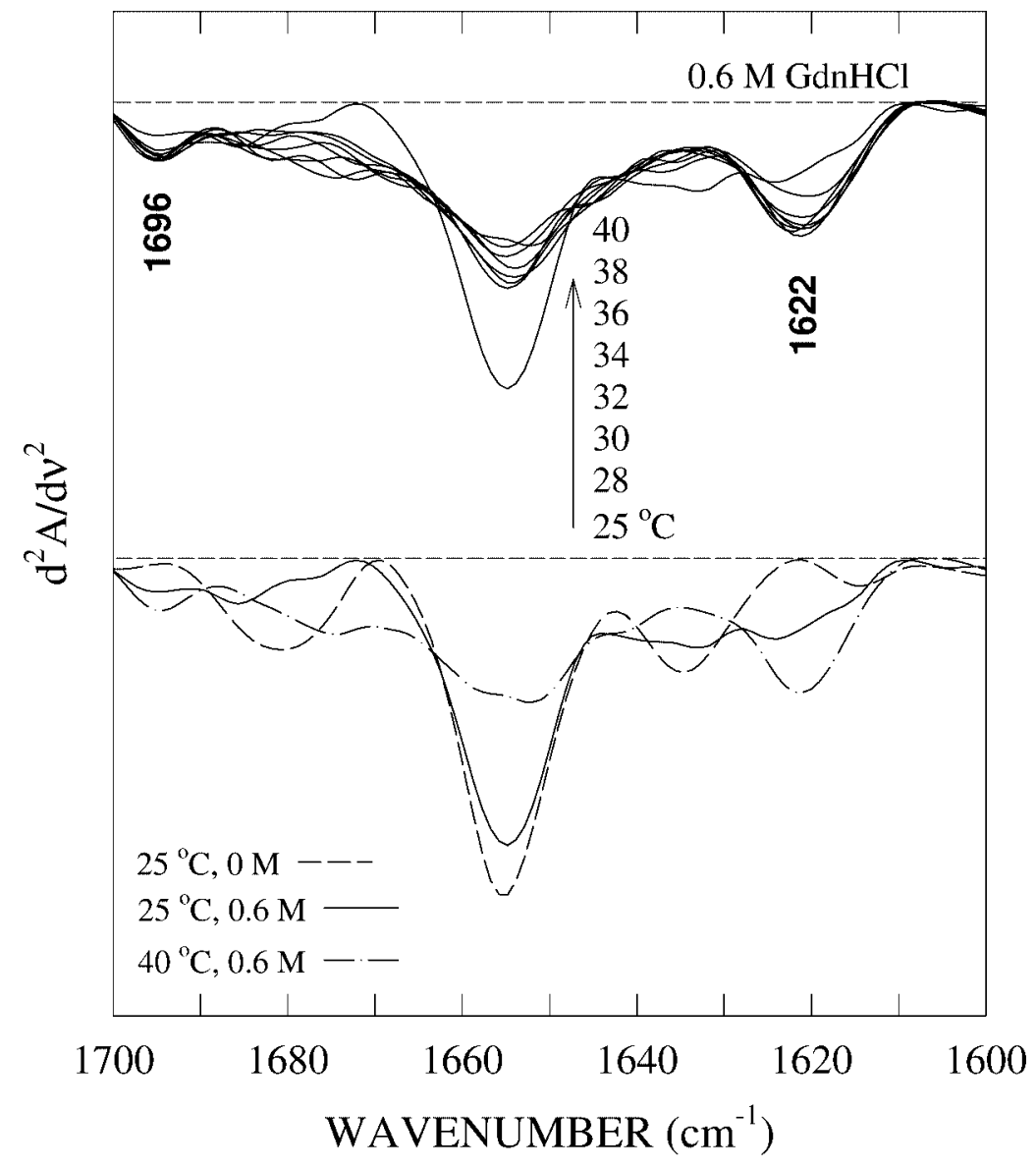

Fig. 8. The second-derivative spectra of yeast enolase in the presence of $0.6 \mathrm{M} \mathrm{gdnHCl}$ as a function of temperature. (Top) The spectra were recorded at $25,28,32,34,36,38$ and $40^{\circ} \mathrm{C}$. (Bottom) Spectra selected for comparison.

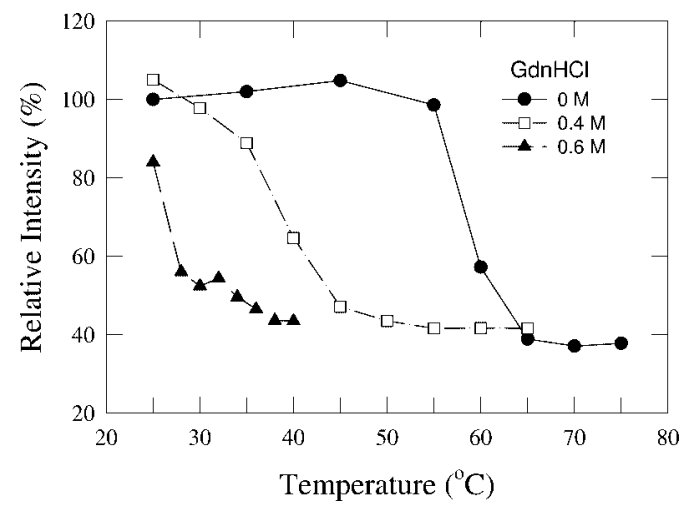

Fig. 9. The plot of relative intensity changes at $1656 \mathrm{~cm}^{-1}$ as functions of temperature in the absence and presence of 0.4 or $0.6 \mathrm{M}$ gdnHCl. 
protein folds and unfolds, scientists have explored a wide range of physical and chemical factors known to perturb protein structures, including temperature, $\mathrm{pH}$, pressure, concentration, ionic strength, chemicals and chemical denaturant by a variety of analytical techniques. However, studies of protein folding/unfolding are often plagued by competing, off-pathway aggregation processes. Protein aggregates are also known to play a critical role in pathology of a large group of diseases called amyloidoses [38, 39]. Human amyloidoses including common neurodegerative diseases such as Alzheimer's disease and Parkinson's disease, as well as systemic diseases such as monoclonal light chain amyloidosis and adult diabetes, have affected the lives of millions of peoples in the United Sates [40-42].

Enolase, a member of the enolase superfamily, is among the few dozens of proteins with a $(\beta \alpha)_{8}$ barrel structure $[12,43,44]$. This structural motif provides researchers with a unique specimen for studying protein folding/unfolding and aggregation process. However, little is known about thermal stability and the chemically induced unfolding of enolase. Most attentions have, so far, been focused on triose-phosphate isomerase, a single domain architectural prototype of the $(\beta \alpha)_{8}$-barrel proteins $[16-18,45]$. In this study, we provide new insight into the structural stability and thermal/chemical denaturation of yeast enolase.

\subsection{Amide I band assignments}

The amide I band assignments for yeast enolase are consistent with the amide I band assignments for the other globular proteins in $\mathrm{H}_{2} \mathrm{O}$ solution [23,24]. However, the assignments for the two bands at $1701 \mathrm{~cm}^{-1}$ (high wavenumber $\beta$-sheet component) and $1661 \mathrm{~cm}^{-1}\left(3_{10}\right.$-helix and type III turn), respectively, are worthy of further discussion.

Despite cautions made by Susi and Byler [46], the presence of a high wavenumber $\beta$-sheet component has often been used as an exclusive indicator of the antiparallel $\beta$-sheet structure by many investigators. Although it is not the best example for proteins with parallel $\beta$-sheet structure due to the presence of a three-stranded antiparallel $\beta$-meander and antiparallel insertion of the $\beta_{2}$-strand, the $\beta$-sheet structure of yeast enolase is predominantly parallel $[10,11]$. Thus, the small but readily detectable high wavenumber $\beta$-sheet component at $1701 \mathrm{~cm}^{-1}$ (Figs 2 and 3) is most likely associated with the parallel $\beta$-sheet structures of the enzyme. It has a higher frequency than those found in the spectra of most, if not all, antiparallel $\beta$-sheet $\left(1689-1698 \mathrm{~cm}^{-1}\right)$ proteins in $\mathrm{H}_{2} \mathrm{O}$ solutions [23,24]. In addition, a similar high wavenumber $\beta$-sheet band has also been observed in the spectra of several other proteins with parallel $\beta$-sheet structures as a part of the 8-fold $\beta \alpha$-barrel motif (unpublished data). Therefore, caution must be reiterated that the co-appearance of a high and a low wavenumber $\beta$-sheet components in the amide I region should not be used as an exclusive indicator of the antiparallel $\beta$-sheet structures in the proteins.

The band component at $1663 \pm 3 \mathrm{~cm}^{-1}$ could arise from several secondary structural elements including $\alpha_{\text {II }}$ (distorted) helix [47,48], $3_{10}$-helix [29,49] and type III turn [23,50]. Unfortunately, the three structures are indistinguishable by infrared spectroscopy for proteins in $\mathrm{H}_{2} \mathrm{O}$ solution [23]. The exact assignment of the $1663 \pm 3 \mathrm{~cm}^{-1}$ band has to be made with additional information from other techniques. In this case, $\mathrm{X}$-ray crystal structure has shown that yeast enolase contains no $\alpha_{\mathrm{II}}$ (distorted) helix. However, it does contain four sections of 310 -helix and seven type III or type III' turns (PBD entries 3ENL and 4ENL). Thus, we can assign the $1661 \mathrm{~cm}^{-1}$ band in the spectrum of the native state to a combination of 310 -helix and type III turns (Table 2).

\subsection{Thermal and chemothermal denaturation}

With its unique $\beta \beta \alpha \alpha(\beta \alpha)_{6}$ barrel structure, yeast enolase exhibited a thermal denaturation process not significantly different from that of proteins with predominant $\alpha$-helix [15] or $\beta$-sheet structure $[51,52]$ 
in $\mathrm{H}_{2} \mathrm{O}$ solution as observed by FT-IR spectroscopy. Similar to many monomeric proteins, the thermal denaturation process of dimeric yeast enolase was highly cooperative, irreversible and describable with a two-state model. The structural transition from a native state (dimer) to denatured aggregates (assumable monomers) occurred within a narrow range of temperatures with a midpoint of $\sim 58^{\circ} \mathrm{C}$ and without any detectable intermediate. This result is comparable to the data reported for TIM from various species [16$18,45]$. The majority of the studies has shown that the thermal denaturation process of TIM is irreversible and tightly linked to the aggregation process, with few exceptions at low protein concentrations and faster scanning rate $[53,54]$. At low protein concentration $(0.01 \mathrm{mg} / \mathrm{ml})$ and a scanning rate greater than $1.0^{\circ} \mathrm{C} \mathrm{min}^{-1}$, the thermal denaturation of TIM is fully reversible [54]. The melting temperatures for the wild type TIMs were generally observed between $54-60^{\circ} \mathrm{C}$ [16-18].

Addition of low concentrations of chemical denaturant $\mathrm{gdnHCl}$ destabilizes the overall structure of the enzyme and promotes structural transition from the native to aggregated state at lower temperatures. The presence of low concentration of $\mathrm{gdnHCl}$ in the solution seems to alter the composition of residual structures of the aggregated state. The second-derivative spectra of thermally aggregated enolase obtained in the presence of $0.4 \mathrm{M} \mathrm{gdnHCl}$ share greater similarity to the spectra recorded in the absence of gdnHCl. However, the spectra of aggregated state in the presence of $0.6 \mathrm{M} \mathrm{gdnHCl}$ differ significantly from the spectra of absence of gdnHCl. The overall band areas associated with the $\beta$-sheet aggregates are much less in the presence of $0.6 \mathrm{M} \mathrm{gdnHCl}$ than that of the absence of $\mathrm{gdnHCl}$.

\subsection{Chemical unfolding}

The lack of clearly defined isosbestic point in the overlaid spectra of unfolding suggests that the gdnHCl-induced equilibrium unfolding of yeast enolase is a multi-state event. The appearance of an intermediate characterized as an aggregate at low concentrations $(0.6-1.0 \mathrm{M})$ of gdnHCl indicates that a partially unfolded enolase is very unstable and prone to aggregate. Aggregates at low concentration of $\operatorname{gdnHCl}(0.8-1.2 \mathrm{M})$ were also reported in the case of TIM [55]. The gdnHCl unfolding profile (Fig. 6) shows that disruption of native $\alpha$-helical structure occurred at early stages of unfolding at gdnHCl concentrations between 0.4 and $1.6 \mathrm{M}$. The midpoint of transition is centered at around 0.8 , which falls in the midpoint range of $0.5-1.1 \mathrm{M} \mathrm{gdnHCl}$ reported for TIM of various species [19,20]. These results suggest that the proteins with similar structural motif share some common features in their thermal and chemical stability. The antiparallel insertion of $\beta_{2}$ strand in the inner $\beta_{8}$-barrel, as well as the $\beta \beta \alpha \alpha(\beta \alpha)_{6}$ arrangement in yeast enolase have not affected the overall conformational stability of the protein in relation to the conformational stability of the archetypal $(\beta \alpha)_{8}$-barrel protein TIM.

The study of gdnHCl-induced unfolding of proteins by FT-IR spectroscopy is limited to the proteins with low chemical resistance to gdn $\mathrm{HCl}$ denaturation $(<3.5 \mathrm{M})$ in $\mathrm{H}_{2} \mathrm{O}$ solution with a $6 \mu$ spacer, due to a strong $\mathrm{C}=\mathrm{N}$ stretching vibration $\left(1675 \mathrm{~cm}^{-1}\right)$ of guanidine molecules [13]. A higher concentration of gdnHCl will block the IR signal in the amide I region to reach the detector, thus preventing the analysis of protein secondary structures. With the proteins of low chemical resistance, FT-IR spectroscopy can provide important structural information about chemical unfolded state that no other techniques currently available are capable of. In the current study, we continue to monitor the amide I spectral changes after the disappearance of the native-like secondary structures. The result shows that the gdnHCl-unfolded state contains structural elements other than random coil, such as turns and loops. In Fig. 5, it is evident that the amide I spectra of the enzyme continue to change after the unfolding transition is complete (gdnHCl $>1.6 \mathrm{M}$ ). Our FT-IR spectroscopic data is consistent with Dill's Heteropolymer theory, which predicts that the denatured state of a protein will continue to expand, as the denatured solution becomes a better 
solvent for the unfolded proteins [37,56]. It is also consistent with the previous reported observation on gdnHCl-induced unfolding of cytochrome $c$ [13].

\section{Acknowledgement}

This work was supported by National Institutes of Health Grant 1R15GM5588901 to A.D.

\section{References}

[1] J.M. Brewer and G. Weber, The reversible dissociation of yeast enolase, Proc. Natl. Acad. Sci. USA 59 (1968), $216-223$.

[2] J.M. Brewer T. Fairwell, J. Travis and R.E. Lovins, An investigation of the subunit structure of yeast enolase, Biochemistry 9 (1970), 1011-1016.

[3] L.D. Faller and A.M. Johnson, Direct measurement of proton release by yeast enolase upon binding magnesium ions, FEBS Lett. 44 (1974), 298-301.

[4] J.M. Brewer, Yeast enolase: mechanism of activation by metal ions, CRC Crit. Rev. Biochem. 11 (1981), $209-254$.

[5] C.C. Chin, J. M. Brewer and F. Wold, The amino acid sequence of yeast enolase, J. Biol. Chem. 256 (1981), $1377-1384$.

[6] J.E. Wedekind, R.R. Poyner, G.H. Reed and I. Rayment, Chelation of serine 39 to $\mathrm{Mg}^{2+}$ latches a gate at the active site of enolase: structure of the bis $\left(\mathrm{Mg}^{2+}\right)$ complex of yeast enolase and the intermediate analog phosphonoacetohydroxamate at 2.1- ̊̊ resolution, Biochemistry 33 (1994) 9333-9342.

[7] F. Wold, Enolase, in: The Enzymes, P.D. Boyer, ed., 3rd edn, Vol. 5, Academic Press, New York, 1971, pp. $499-538$.

[8] D.P. Hanlon and E.W. Westhead, Kinetic studies on the activation of yeast enolase by divalent cations, Biochemistry 8 (1969), 4255-4260.

[9] L.D. Faller, B.M. Baroudy, A.M. Johnson and R.X. Ewall, Magnesium ion requirements for yeast enolase activity, Biochemistry 16 (1977), 3864-3869.

[10] L. Lebioda, B. Stec and J.M. Brewer, The structure of yeast enolase at 2.25-Åresolution. An 8-fold $\beta+\alpha$-barrel with a novel $\beta \beta \alpha \alpha(\beta \alpha)_{6}$ topology, J. Biol. Chem. 264 (1989), 3685-3693.

[11] B. Stec and L. Lebioda, Refined structure of yeast apo-enolase at 2.25 Å resolution, J. Mol. Biol. 211 (1990), $235-248$.

[12] R.R. Copley and P. Bork, Homology among $(\beta \alpha)_{8}$ barrels: implications for the evolution of metabolic pathways, J. Mol. Biol. 303 (2000), 627-640.

[13] B.E. Bowler, A. Dong and W.S. Caughey, Characterization of the guanidine-HCl denaturation state of iso-1-cytochrome $c$ by infrared spectroscopy, Biochemistry 33 (1974), 2402-2408.

[14] A. Dong, S.J. Prestrelski and J.F. Carpenter, Infrared spectroscopic studies of lyophilization- and temperature-induced protein aggregation, J. Pharm. Sci. 84 (1995), 415-424.

[15] A. Dong, T.W. Randolph and J.F. Carpenter, Entrapping intermediates of thermal aggregation in alpha-helical proteins with low concentration of guanidine hydrochloride, J. Biol. Chem. 275 (2000), 27 689-27 693.

[16] W. Shliebs, N. Thanki, R. Jaenicke and R. Wierenga, A double mutation at the tip of the dimer interface loop of triosephosphate isomerase generates active monomers with reduced stability, Biochemistry 36 (1997), 9655-9662.

[17] M. Alvarez, J.P. Zeelen, V. Mainfroid, F. Rentier-Delrue, J.A. Martial, L. Wyns, R.K. Wierenga and D. Maes, Triosephosphate isomerase (TIM) of the psychrophilic bacterium Vibrio marinus, J. Biol. Chem. 273 (1998), 2199-2206.

[18] B. Gopal, S.S. Ray, R.S. Gokhale, H. Balaram, M.R.N. Murthy and P. Balaram, Cavity-creating mutation at the dimer interface of Plasmodium falciparum triosephosphate isomerase: Restoration of stability by disulfide cross-linking of subunits, Biochemistry 38 (1999), 478-486.

[19] A.W.M. Rietveld and S.T. Ferreira, Kinetics and energetics of subunit dissociation/unfolding of TIM: the importance of oligomerization for conformational persistence and chemical stability of proteins, Biochemistry 37 (1998), 933-937.

[20] M.E. Chánez-Cárdenas, D.A. Fernández-Velasco, E. Vázquez-Contreras, R. Coria, G. Saab-Rincon and R. PérezMontfort, Unfolding of triosephosphate isomerase from Trypanosoma brucei: identification of intermediates and insight into the denaturation pathway using tryptophan mutants, Arch. Biochem. Biophys. 399 (2002), 117-129.

[21] M.J. Holland, J.P. Holland, G.P. Thill and K.A. Jackson, The primary structures of two yeast enolase genes. Homology between the $5^{\prime}$ noncoding flanking regions of yeast enolase and glyceraldehyde-3-phosphate dehydrogenase genes, J. Biol. Chem. 256 (1981), 1285-1395.

[22] Y. Nozaki, The preparation of guanidine hydrochloride, Methods Enzymol. XXVI (1972), Part C, pp. 43-50.

[23] A. Dong and W.S. Caughey, Infrared methods for study of hemoglobin reactions and structures, Methods Enzymol. 232 (1994), 139-175. 
[24] A. Dong, P. Huang and W.S. Caughey, Protein secondary structures in water from second-derivative amide I infrared spectra, Biochemistry 29 (1990), 3303-3308.

[25] A. Dong, B. Caughey, W.S. Caughey, K.S. Bhat and J.E. Coe, Secondary structure of the pentraxin female protein in water determined by infrared spectroscopy: effects of calcium and phosphorylcholine, Biochemistry 31 (1992), 9364-9370.

[26] B.S. Kendrick, A. Dong, S.D. Allison, M.C. Manning and J.F. Carpenter, Quantitation of the area of overlap between second-derivative amide I infrared spectra to determine the structural similarity of a protein in different states, J. Pharm. Sci. 85 (1996), 155-158.

[27] S.J. Prestrelski, N. Tedeschi, T. Arakawa and J.F. Carpenter, Dehydration-induced conformational transitions in proteins and their inhibition by stabilizers, Biophys. J. 65 (1993), 661-671.

[28] S.J. Prestrelski, T. Arakawa and J.F. Carpenter, Separation of freezing- and drying-induced denaturation of lyophilized proteins using stress-specific stabilization. II. Structural studies using infrared spectroscopy, Arch. Biochem. Biophys. 303 (1993), 465-473.

[29] S. Krimm and J. Bandekar, Vibrational spectroscopy and conformation of peptides, polypeptides and proteins, Adv. Protein. Chem. 38 (1986), 181-364.

[30] H. Susi and D.M. Byler, Resolution-enhanced Fourier transform infrared spectroscopy of enzymes, Methods Enzymol. 130 (1986), 290-311.

[31] B.R. Singh, Basic aspects of the technique and applications of infrared spectroscopy of peptides and proteins, in: Infrared Analysis of Peptides and Proteins, Principles and Applications, B.R. Singh, ed., ACS Symposium Series 750 (2000), pp. 2-37.

[32] Y.N. Chirgadze, O.V. Fedorov and N.P. Trushina, Estimation of amino acid residue side-chain absorption in the infrared spectra of protein solutions in heavy water, Biopolymers 14 (1975), 679-694.

[33] S.J. Prestrelski, D.M. Byler and M.N. Liebman, Comparison of various molecular forms of bovine trypsin: correlation of infrared spectra with X-ray crystal structures, Biochemistry 30 (1991), 133-143.

[34] C.L. Wilder, A.D. Friederich, R.O. Potts, G.O. Daumy and M. L. Francoeur, Secondary structural analysis of two recombinant murine proteins, interleukins $1 \alpha$ and $1 \beta$ : is infrared spectroscopy sufficient to assign structure?, Biochemistry 31 (1992), 27-31.

[35] P.S. Kim and R.L. Baldwin, Intermediates in the folding reactions of small proteins, Annu. Rev. Biochem. 59 (1990), 631-660.

[36] K.A. Dill and D. Shortle, Denatured states of proteins, Annu. Rev. Biochem. 60 (1991), 795-825.

[37] D. Shortle, The denatured state (the other half of the folding equation) and its role in protein stability, FASEB J. 10 (1996), 27-34.

[38] J.W. Kelly, Alternative conformations of amyloidogenic proteins govern their behavior, Curr. Opin. Struct. Biol. 6 (1996), $11-17$.

[39] C.M. Dobson, Protein misfolding, evolution and disease, Trends Biochem. Sci. 24 (1999), 329-332.

[40] J.D. Sipe, Amyloidosis, Ann. Rev. Biochem. 61 (1992), 947-975.

[41] R.W. Carrell and B. Gooptu, Conformational changes and disease - serpins, prions and Alzheimer's, Curr. Opin. Struct. Biol. 8 (1998), 799-809.

[42] E.H. Koo, P.T. Lansbury Jr. and J.W. Kelly, Amyloid diseases: abnormal protein aggregation in neurodegeneration, Proc. Natl. Acad. Sci. USA 96 (1999), 9989-9990.

[43] Y. Sergeev and B. Lee, Alignment of $\beta$-barrels in $(\beta \alpha)_{8}$ proteins using hydrogen-bonding pattern, J. Mol. Biol. 244 (1994), $168-182$.

[44] A.E. Todd, C.A. Orengo and J.M. Thornton, Evolution of function in protein superfamilies, from a structural perspective, J. Mol. Biol. 307 (2001), 1113-1143.

[45] J. Sun and N.S. Sampson, Understanding protein lids: kinetic analysis of active hinge mutants in triosephosphate isomerase, Biochemistry 38 (1999), 11 474-11 481.

[46] H. Susi and D.M. Byler, Fourier transform infrared study of proteins with parallel $\beta$-chains, Arch. Biochem. Biophys. 258 (1987), 465-469.

[47] S. Krimm and A.M. Dwivedi, Infrared spectrum of the purple membrane: clue to a proton conduction mechanism?, Science 216 (1982), 407-408.

[48] M. Duñach, E. Padros, A. Muga and L.R. Arrondo, Biochemistry 28 (1989), 8940-8945.

[49] D.F. Kennedy, M. Crisma, C. Toniolo and D. Chapman, Studies of peptides forming $33_{10}$ - and $\alpha$-helices and $\beta$-bend ribbon structures in organic solution and in model biomembranes by Fourier transform infrared spectroscopy, Biochemistry $\mathbf{3 0}$ (1991), 6541-6548.

[50] S.C. Yasui, T.A. Keiderling, G.M. Bonora and C.C. Toniolo, Vibrational circular dichroism of polypeptides, V. A study of $3_{10}$-helical-octapeptides, Biopolymers 25 (1986), 79-89.

[51] A. Dong, B.S. Kendrick, L. Kreilgård, J. Matsuura, M.C. Manning and J.F. Carpenter, Spectroscopic study of secondary structure and thermal denaturation of recombinant human factor XIII in aqueous solution, Arch. Biochem. Biophys. 347 (1997), 213-220. 
[52] A. Dong, J.D. Meyer, J.L. Brown, M.C. Manning and J.F. Carpenter, Comparative Fourier transform infrared and circular dichroism spectroscopic analysis of $\alpha 1$-proteinase inhibitor and ovalbumin in aqueous solution, Arch. Biochem. Biophys. 383 (2000), 148-155.

[53] V. Mainfroid, P. Terpstra, M. Beauregard, J.-M. Frère, S.C. Mande, W.G.J. Hol, J.A. Martial and K. Goraj, Three hTIM mutants that provide new insights on why TIM is a dimer, J. Mol. Biol. 257 (1996), 441-456.

[54] C.G. Benítez-Cardoza, A. Rojo-Domínguez and A. Hernández-Arana, Temperature-induced denaturation and renaturation of triosephosphate isomerase from Saccharomyces cerevisiae: Evidence of dimerization coupled to refolding of the thermally unfolded protein, Biochemistry 40 (2001), 9049-9058.

[55] R.S. Gokhale, S.S. Ray, H. Balaram and P. Balaram, Unfolding of Plasmodium falciparum triosephosphate isomerase in urea and guanidinium chloride: evidence for a novel disulfide exchange reaction in a covalently cross-linked mutant, Biochemistry 38 (1999), 423-431.

[56] D.O. Alonso and K.A. Dill, Solvent denaturation and stabilization of globular proteins, Biochemistry 30 (1991), 5974 5985.

[57] L. Lebioda and B. Stec, Crystal structure of holoenolase refined at 1.9 Å resolution: trigonal-bipyramidal geometry of the cation binding site, J. Am. Chem. Soc. 111 (1989), 8511-8513. 


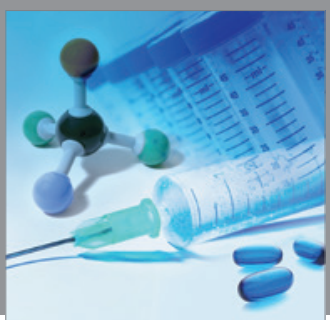

International Journal of

Medicinal Chemistry

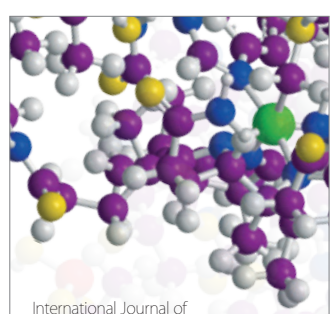

Carbohydrate Chemistry

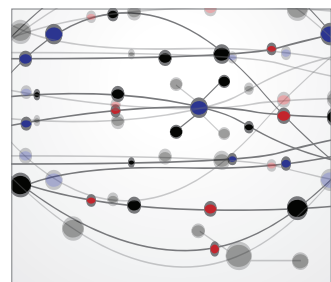

The Scientific World Journal
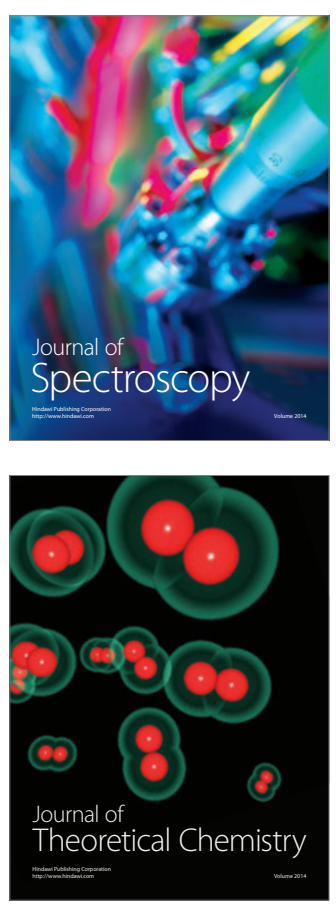
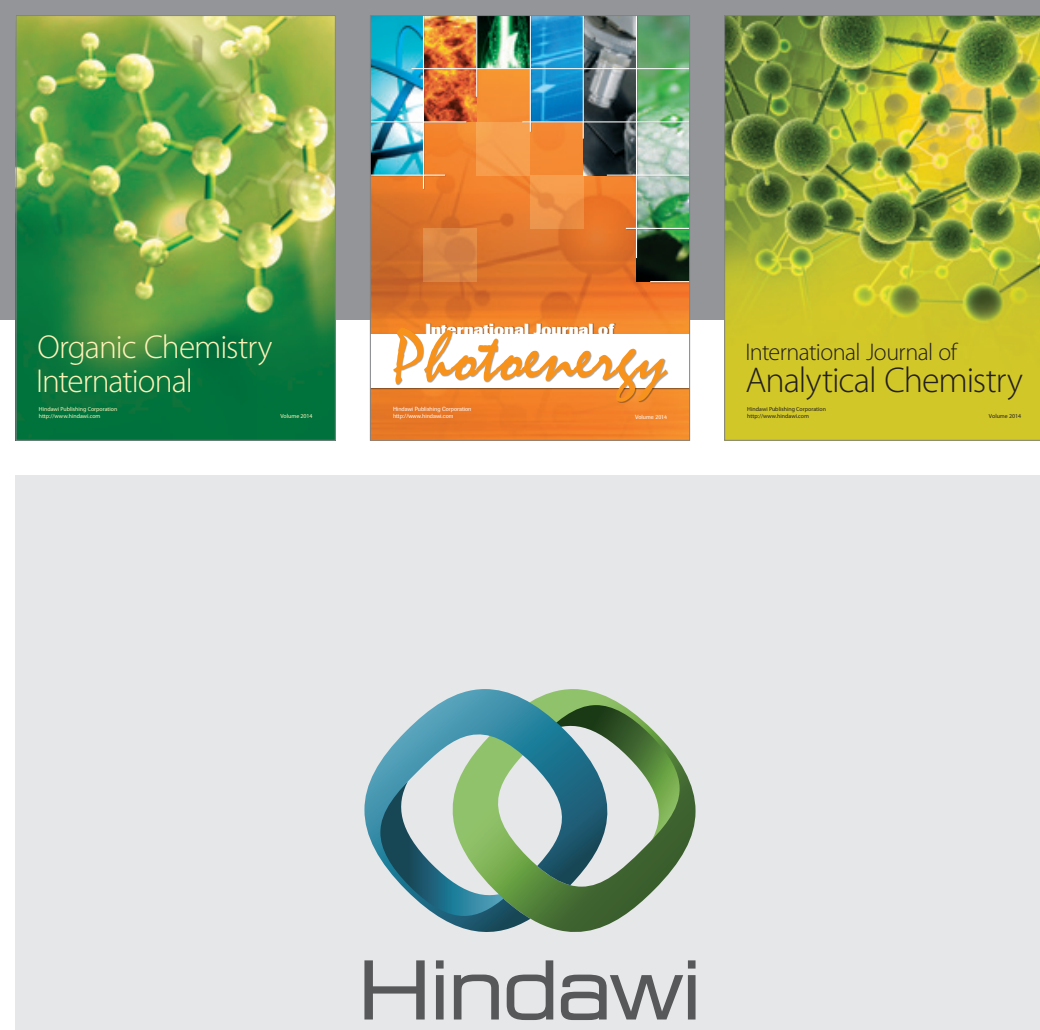

Submit your manuscripts at

http://www.hindawi.com
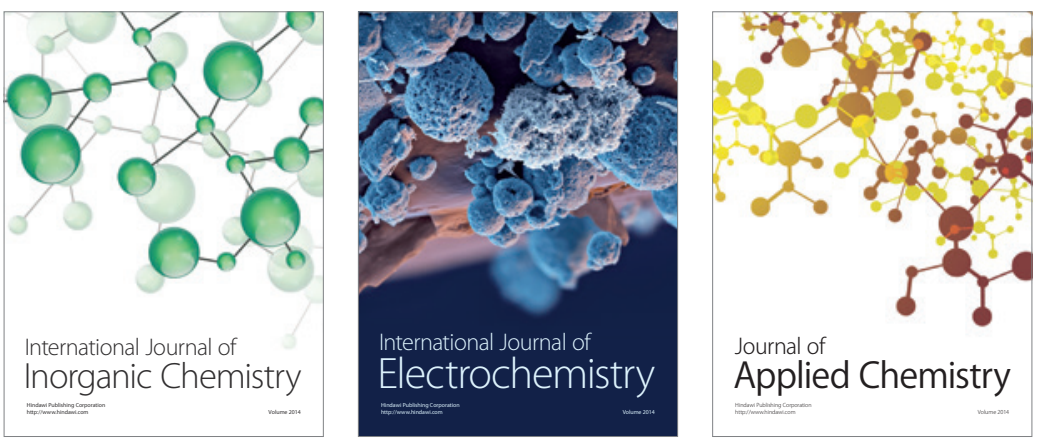

Journal of

Applied Chemistry
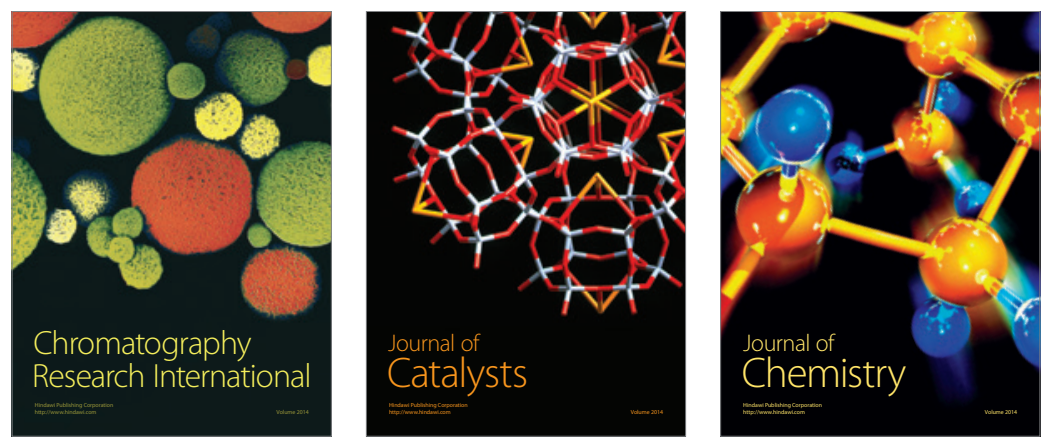
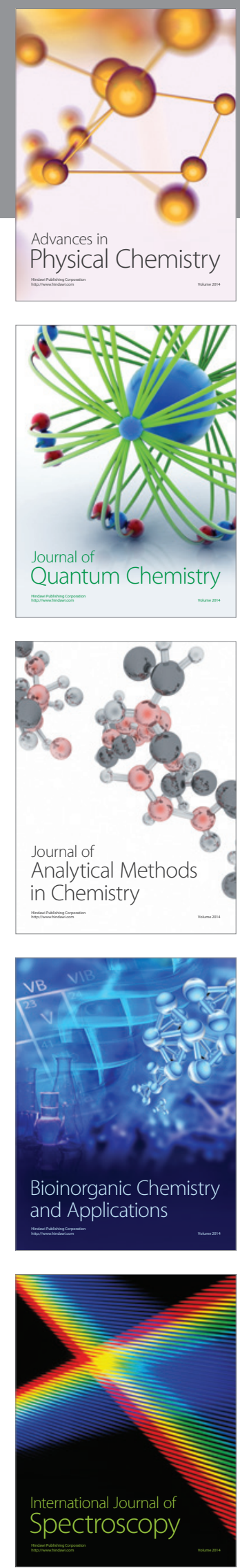